\title{
КРЕДИТНЫЙ ЧАС КАК ЭЛЕМЕНТ СИСТЕМЫ ВЫСШЕГО ОБРАЗОВАНИЯ США
}

\author{
П.А. Богданова \\ Московский гуманитарный университет
}

Аннотация: В данной статье рассматривается один из значимых элементов системы высшего образования США на современном этапе, а также даётся его характеристика.

Ключевые слова: система выстего образования США; кредитный час; система оценивания

\section{CREDIT HOUR AS AN ELEMENT OF THE US HIGHER EDUCATION SYSTEM}

\author{
P.A. Bogdanova \\ Moscow University for the Humanities
}

\begin{abstract}
This article examines one of the most important elements of the US higher education system at the present stage, and gives its characteristics.

Keywords: higher education system of the United States; credit hours; assessment system
\end{abstract}

В настоящий момент из-за влияния глобализации в Российской Федерации происходит множество изменений во многих сферах. Система высшего образования не стала исключением. Предпосылками таких изменений на фоне цифровизации общества стали новые требования рынка труда и, в том числе, наличие у работников необходимых компетенций.

Российская Федерация на основе своего многолетнего опыта и традиций модернизирует сферу высшего образования, опираясь на положительный опыт других стран, в том числе, и на опыт США. Однако, нельзя не принимать во внимание тот факт, что в каждой стране существуют свои особенности, характерные для национальных систем высшего образования. Именно поэтому изучение таких особенностей является актуальной задачей для улучшения образовательного процесса в высшей школе.

Одним из элементов высшего образования, характерным исключительно для США, является кредитный час (credit hour). Американские преподаватели на уровне среднего и высшего образования пользуются различными формулами для расчёта, записи и интерпретации суммы набранных учебных кредитов, которые студенты накапливают с помощью получения сертификатов, дипломов, степеней и других квалификаций. Этот элемент в системе высшего образования США имеет множество названий: a semester credit hour, $\mathrm{SCH}$, college credit (hour), unit, в русском языке этот термин также встречается под названием: «кредит», «кредитная единица» или «кредитный час». В российской системе высшего образования аналога этой условной единицы на настоящий период времени не существует. Итак, под этим термином подразумевают как работу с 
преподавателем или научным руководителем, так и самостоятельные занятия. Конкретное количество зачётных часов начисляется студенту в конце каждого семестра.

Сама кредитная единица для студентов означает определенное количество аудиторных часов, отведенных на прослушанный курс в высшей школе. Зачастую объём кредитного часа, который также известен под названием зачётная единица Карнеги, в течение семестра составляет один академический час в неделю. (Cambridge Dictionary).

Кредитный час - это единица измерения, которая показывает, сколько работы учащийся выполняет в течение семестра. Студенты награждаются кредитом за занятия на основе единицы Карнеги. Это определяет кредитную единицу семестра, равную минимум трем часам работы в неделю в течение семестра (Менеджмент и экономика труда, 2006).

Как правило, при получении степени бакалавра студенту нужно будет заработать от 110 до 140 кредитных часов за 4 года. Если учащийся проходит магистратуру, это может занять от 30 до 40 кредитных часов в соответствии с программой.

Студенту нужно знать, что из себя представляет credit hour, с целью выбрать для себя оптимальную по стоимости и содержанию программу обучения, составить для себя наилучший, не перегруженный, но в то же время и не слишком простой, учебный план, а также понимать, каким образом будет оцениваться его успеваемость.

В отношении credit hour необходимо учитывать несколько важных моментов. Во-первых, credit unit суммирует всю выполненную работу, и может не совпадать с фактическим пребыванием в высшей школе или учебными часами. Во-вторых, высшие учебные заведения в США используют кредитные часы и единицы для отражения всех видов академической деятельности, а не только преподаваемых курсов. Например, в документах студента докторантуры будут содержаться кредиты, полученные за самостоятельно проведённые исследования, которые довольно часто выражаются так, как если бы такой студент был внесён в список студентов, посещающих занятия в самом учебном заведении, даже при условии, что фактическая работа является независимым исследованием.

Кредиты присваиваются обучающимся в высших школах за учебные модули, которые условно можно разделить на пять основных типов: лекционносеминарские, лабораторные, стажёрские, исследовательские и практические (Бабичев, Петров, 2007).

В соответствии с каждым видом учебного модуля учащийся может получить разное количество кредитных часов (Филиппович, 2005).

Лекционно-семинарский модуль зачастую равняется одному часу очной работы с преподавателем высшей школы, и в то же время- двум часам 
самостоятельных занятий учащегося каждую неделю на протяжении семестра.

Лабораторный модуль эквивалентен одному лекционному часу или работе с научным руководителем, одному или двум часам лабораторной работы и двум часам самостоятельной учёбы каждую неделю на протяжении семестра.

Практический модуль включает в себя три-четыре часа практической работы с преподавателем или самостоятельной практической работе каждую неделю в течение семестра (Филиппович, 2005).

Исследовательский модуль приравнивают к одному кредитному часу практики.

Модуль стажировки - это кредитные часы, которые студент зарабатывает в процессе прохождения стажировки. Обычно стажировка является результатом договорённости между работодателем студента и администрацией вышей школы. Данный модуль рассчитывается, в большинстве случаев, как и практический модуль (Филиппович, 2005).

Статус зарегистрированного студента обычно определяется как зачисление в определенный семестр или четверть на определенное минимальное количество кредитных часов, которые назначаются для любого типа обучения, признанного и требуемого факультетом, а плата за обучение обычно рассчитывается по стоимости обучения за кредитный час. Обучение на дневном отделении обычно составляет 15 кредитных часов в семестр или 30 кредитных часов в учебный год. Некоторые учебные заведения устанавливают фиксированную ставку для студентов дневного отделения. Таким образом учащийся, который занимается более 15 кредитных часов в семестр, заплатит ту же стоимость, что и учащийся, который возьмёт ровно 15 кредитных часов. Студент заочного отделения, получающий меньше 12 кредитных часов, вынужден будет платить за каждый кредитный час, помимо суммы за зачисление в школу и студенческим сборам (The University of Arizona, Academic Policies, Credit Definitions, 2020).

В университете или колледже в Соединённых Штатах студенты чаще всего получают кредитные часы на основе количества аудиторных часов в неделю на один семестр. Аудиторные часы подразумевают любую лекцию или лабораторное время, когда студенты находятся в прямом контакте с преподавателем. Несмотря на продолжительность дисциплины, и в зависимости от штата и юрисдикции, кредитный час семестра (semester credit hour (SCH)) составляет в среднем 15-16 аудиторных часов в семестр. Большинство дисциплин в колледжах и университетах составляют 3 семестровых кредитных часа равные 45-48 аудиторным часам, поэтому обычно занятия в аудитории по одной дисциплине проходят 3 раза в неделю, в течение семестра, длящегося около 15 недель.

Прежде всего кредит является подтверждением того, что студент прошёл курс обучения в школе, колледже или университете и является мерой времени, затраченным студентом на учебный процесс в высшей школе. 
Кредиты отражают еженедельную учебную нагрузку студента. Однако, начисляются они не еженедельно, а за весь семестр, который в среднем длится 1516 недель. Таким образом, если в расписании обучающегося стоят три аудиторных занятия в неделю, то по итогу студент получит 3 зачётные единицы. Тем не менее, для того чтобы получить эти зачётные единицы, студенту необходимо провести 45 часов аудиторной работы и 90 часов потратить на самостоятельное изучение материала.

В зависимости от программы обучения зачетные часы начисляются за работу в музыкальной, художественной или театральной студии, в больнице, за преподавание, проведение социологических опросов, исследовательскую деятельность и так далее. В большинстве случаев от студента требуется сдать блок практических заданий по прикладным программам, который состоит из трех практических занятий в неделю. Они позволяют студенту получить 3 кредита за семестр, что составляет от 135 до 180 часов учебной нагрузки.

Домашнее задание - это то время, которое тратит студент, используя материалы, полученные в аудитории, без контроля преподавателя. Домашние задания в системе высшего образования США включают в себя изучение конспектов, сделанных во время лекции, дополнительное чтение специальной литературы, письменные работы по дисциплинам или другие действия студента, которые происходят без координации с преподавателем, например, лабораторные работы или сбор информации для научной работы. Студенты обычно должны тратить около трёх часов на выполнение домашнего задания за каждый час, проведённый в аудитории.

Кредит на учебно-производственное обучение (studio course) и практические занятия (laboratory course), а также на такую дисциплину, как физическая культура обычно меньше, чем на лекционные занятия в высшей школе. Довольно часто это один кредит на каждые два-три академических часа, проведённых на практических или учебно-производственных занятиях, в зависимости от правил каждого университете или колледжа. Однако, для некоторых практических занятий, таких как обучение для получения лицензии на преподавательскую деятельность, студент может заработать всего от 8 до 10 кредитов за семестр, учитывая 40 часов, проведённых за учёбой, в неделю.

Помимо привычных для нас оценок в университетах и колледжах США, кредиты играют немаловажную роль для успеваемости обучающегося. Для того, чтобы вычислить средний балл - GPA студента в высшей школе вместе с кредитами, каждая оценка по определённой дисциплине умножается на балл по этому кредиту, как указывает А.Ю. Филиппович в работе «Кредитные системы в образовании: аспект автоматизации»: «GPA $=\mathrm{k} \times \mathrm{d}$, где $k$ - количество кредитов часов по какому-то одному предмету, изучаемому в данном семестре; $d$ - оценка студента по этому предмету» (Филиппович, 2005). После этого всё вместе скла- 
дывается и делится на общее количество кредитов. Например, получив оценку «В» (аналог оценки «4»/《хорошо» в российской системе образования) и имея четыре кредита, студент имеет 16 балла успеваемости. Именно они в последствии складываются, а затем делятся на общее количество кредитов для получения среднего балла. В некоторых университетах берутся во внимание и оценки с плюсами, как A+ или В+, которые добавляют ещё пол балла. В других сумма среднего балла округляется до целой цифры. Каждый университет оставляет за собой право на выбор того, как рассчитать средний балл учащегося, однако, в основном правила практически не отличаются.

Руководство высших школ могут требовать, чтобы оценки за некоторые дисциплины были выше, чем минимальный балл. В ином случае, оценка «D» (российский аналог «3»/«удовлетворительно») будет увеличивать общее количество полученных кредитов, в отличие от оценки «F» (российский аналог «2»/«неудовлетворительно»).

Минимальное количество кредитных единиц для получения степени по программе бакалаврита составляет от 120 до 140, по программе магистратуры от 33 до 54.

В среднем очные программы бакалавриата предполагают 15 кредитных часов в семестр, что соответствует 30 кредитным часам за учебный год. За весь период обучения на бакалавриате академическая нагрузка составляет не меньше 5400 часов, по профилям, не связанным с техникой, искусством, медициной и наукой.

На основе собранных кредитов приемная комиссия делит студентов на новый, второй, средний и старший курсы.

Таблица 1

\section{Классификация студентов, обучающихся на бакалавра}

(Филиппович А.Ю., 2005)

\begin{tabular}{|c|c|}
\hline Количество credit hours & Классификация студентов \\
\hline $0-31$ & Новый студент \\
\hline $32-63$ & Студент второго курса \\
\hline $64-95$ & Студент среднего курса \\
\hline Более 96 & Студент старшего курса \\
\hline
\end{tabular}

В состав магистерских программ входят не менее 30 кредитных часов, иногда их число доходит до 64, что в итоге даёт около 4000 часов академической нагрузки, и с научным руководителем, и без него, за весь период обучения.

Кредитные часы в США присваиваются даже обучающимся на уровне аспирантуры, которые зачастую занимаются исследованиями и не берут часы 
работы с преподавателями высших школ. В программу аспирантуры входят более 8000 часов академической нагрузки за всё время обучения, в соответствии с темой и предметом исследования, которые включают в себя углублённое изучение предметов, лабораторную и исследовательскую работу самостоятельно и вместе с научным руководителем.

Преподаватели в колледжах и университетах обычно имеют 12 семестровых кредитных часов за семестр. Преподаватели, работающие с выпускниками или с большими классами (100 или более студентов в потоковых группах), могут рассчитывать на снижение нагрузки. Преподаватели в исследовательских университетах, какправило, имеют официальнуюучебнуюнагрузку в 12 кредитных часов в семестр, но их фактическая нагрузка снижается из-за необходимости значительных публикаций, опубликованных в рецензируемых журналах.

В то время как преподавательская нагрузка почти повсеместно основана на количестве преподаваемых кредитных часов, работа преподавателей по техническим программам «астрономических часов» в технических и общественных колледжах имеет рабочую нагрузку, которая больше напоминает преподавание в средней школе, так что преподаватели в общественных колледжах обычно отрабатывают 15 или более кредитных часов за семестр (5 дней в неделю по 3 часа в день).

В заключении, стоит отметить, что кредитный час как элемент системы высшего образования США играет немаловажную роль. Во-первых, credit hour является одним из ключевых аспектов, помогающих студенту выбрать оптимальную для себя программу обучения и учебный план в университете. Bo-вторых, credit hour является свидетельством прохождения студентом курса обучения в высшем учебном заведении, а также мерой времени, которое студент затратил на процесс обучение. Можно считать credit hour универсальной системой оценивания, т.к. он отражает все виды академической работы и еженедельную учебную нагрузку, и успеваемость студента.

\section{СПИСОК ЛИТЕРАТУРЫ}

Cambridge Dictionary [Электронный ресурс] // URL: https://dictionary.cambridge. org/us/spellcheck/english/?q=credit+unit (дата обращения: 15.08.2020).

The University of Arizona, Credit Definitions // Academic Policies. 2020. [Электронный ресурс] URL: https://catalog.arizona.edu/policy/credit-definitions (дата обращения: 04.09.2020).

Бабичев Ю., Петров В. (2007) Учет трудоемкости самостоятельной работы студентов при переходе на зачетные единицы // Высшее образование в России. №6. C. 26-41.

Менеджмент и экономика труда. (2006) Новый англо-русский толковый словарь ABBYY Software. Экономическая школа. 
Филиппович А.Ю. Кредитные системы в образовании: аспект автоматизации. М.: УМК по специальности ИТО, 2005. - 204 с.

Богданова Полина Александровна - магистрант 3 курса, кафедра педагогики и психологии высшей школы Московского гуманитарного университета. Научный руководитель- доктор педагогических наук, профессор Л.В Романюк. Адрес: 111395, Россия, г. Москва, ул. Юности, д. 5. Тел.: +7 9266576538 Эл.адрес: bogdanovapolina96@yandex.ru

Bogdanova Polina Alexsandrovna - graduate student, 3 course, psychology and tertiary teaching of Moscow University for the Humanities. Research adviser - EdD, Professor L.V. Romanyuk Adress: Moscow, Yunosti street, 5. Tel.: +7 9266576538 E-mail: bogdanovapolina96@yandex.ru 